تأثير استخدام تدريبات كروس فيت علي الجه البذني والتحمل الخاصوعلاقتهما بالتكنيك الهجومي لبعض مهارات الناجي وازا للاعبي رياضة الجودو

*".أم.د/إيمان عسكر احمد

مشكلة البحث واهميته

يتميز العصر الحديث بالتطور العمهوالمستمر في مجال النشاط الرياضى من جميع الجوانب المهارية والخططيه والنفيسة والبدنية ، ويرجع ذلك الي الاستفادة من نتائج الابحاث التطبيقيه في عملية التدريب الرياضي والبحث الدائم عن افضل الطرق والوسائل المساعده لتطوير مستوى ادء اللاعبين

وبذلك اصبح للتدريب الرياضى اصوله وقواعده التي يستند عليها ويستمد منها مادته نتيجة للتطور التكنولوجى لكي يصل باللاعب الرياضى الي المستويات الرياضية العالية في نوع معين من انواع الانشطة التخصصية لانه يشكل اساس رياضة المستويات او رياضة البطولات ( 43: 36 )

ومن هذا المنطلق يذكر "عصام عبدالحميد" (2000م) ان كل متابع لتطوير المستويات الرياضة في العالم ومتأملاتلك الاداءات يدرك ان للتدريب الرياضى شان عظيم في اعداد وصياغة وتطوير القدرات الانسانية وابعادها المختلفة من اجل تفجير اقصى ما يمكن من قدرات وما بداخل اللاعب من طاقات في اتجاه الهدف المنشود (15 : 41 (

ويرى إدوارددياس"Edward Dias"( 2008م) ان هناك العديد من الطرق التى تستخدم في اعداد اللاعبين للوصول الي الانجاز الرياضى ، ولذلك تعتبر تدريبات كروس فيت احدى هذه الطرق التى لها تأثيرات ايجابية على الاداء (42: 23)

وتعد كروس فيث من ابرز التدريبات التي تزيد من قدرة العضلات على التحمل وهي عبارة عن مجموعة دائرية من التمارين التي تستهف العضلات الاساسية في الجسم و تضم كروس فيت تثكيلة *استاذ مساعد بقسم الرياضات المائية والمنازلات - كلية التربية الرياضية للبنات جامعة الزقازيق 
مختلفة من التمارين الرياضية المختلفة تبدا اولا بتمارين الاحماء ثم ينتقل المتدرب لابرز التمارين مثل تمارين البطن وتمارين العقلة وتدريبات رفع الاثقال وتدريبات الايروبكس والجمباز ، وتتم ممارسة هذه التمارين بالتكرار دون توقف او راحة ايجابية طول وحدة التدريب المحدة وعندما يصل الثخص لاعلى المستويات ينتقل الي المستويات المتقدمة اي بمارس المتدرب ما يعرف بالاربعة اوقات ، هذا يعنى ان يقوم الثخص باختبار اربعة تمارين لممارستهابعدد معين ولفترة محددة مثل ممارسة تمارين بليو سوفت بوكس خمس مرات ثم بعد ذلك باتث روب خمس مرات ومن بعدها ممارسة تمرين الركض لمدة عشر مرات ثم تمارين الاستب لعشرة دقائق وهكذا ، فضلا عن تمارين القرفصاء مع الققز في الهواء مما يعمل على زيادة قوة العضلات مع رفع قوى التحمل للمفاصل على وجه التحديد (48 )

ويشير "علي جلال الدين"(2006م) الي ان الاجهاد هو حالة يقع فيها الفرد تحت ضغط انفعالي او بدني وعادة ما تحدث نتتيجة لمؤثرات خارجيه حيث تسهم في حالة من التوتر البدني للفرد (18: 437 )

ويذكر "هاريس haris"(2001م) ان حامض اللاكتيك احد الاسباب الرئيسية التى تسبب الاجهاد البدني ويرتبط ذلك بظاهرة التعب فالاجهاد البدني اثناء الحالة الطبيعية يتراوح مابين 0.3 : 0.6 \% وان مصدر حامض اللاكتيك هو الجليكوجين ومن ثم زيادته تؤدي الي الاقلال من مخزون المواد الكربوهيدراتية ولا يعتبر نقص الجليكوجين المخزون بالعضلة اساس لاجهادها لان العضلة بعد اجهادها لا تتقبص ولا تستطيع ان تستخدم الجليكوجين المتوفر بها ،ويعزيللك الي قلة الانزيم الخاص بتكسير الجيكوجين هو مايحدث نتيجة لزيادة الحموضة بالعضلة (44:121 ، 122)

ويشير كلا من"ابو العلا احمد عبدالفتاح واحمد نصر الدين رضوان"( 2003م) انه يقل انتاج حمض اللاكتيك اثناء النشاط البدني عند زيادة استهلاك الاكسجين حيث انه عند ذلك يتم اكسدة ايونات هيدرجين و بيروفيك اكثر والناتجة عن التمثيل اللاهوائي لتحول داخل الميتوكندريا الي CO2، H2O امافي حالة عدم كفاية الاكسجين فان البيروفيك وايونات الهيدروجين يتحولان لتكوين لاكتات الدم ، وان الجهاز الدوري يساعد في التخلص من اللاكتات عن طريق زيادة الدفع القلبي او عن طريق زيادة كثافة الشعيرات الدموية وتوزيع سريان الدم وكل ذلك يعمل علي سريان الدم خلال العضلات لفترة زمنية اطول مما يسمح بزيادة انتشار اللاكتات في الدم الذي يقوم بنقلها الي القلب والكبد والعضلات الاخري الغسر عاملة ، وعندما يزداد تجمع 
اللاكتات في العضلة وتحدث الحمضية يشعر اللاعب بالالم وعندئذ يستطيع اللاعب المدرب علي تحمل هذا الالم والاستمرار في الاداء حيث يتم ذلك من خلال تحسن سعة المنظمات الحيوية ( 1 : 166 ، 167 ) كما يضيف "عحم صبحي عبد الحميد" (2005م) ان حامض اللاكتيك الناتج عن الجلكزة اللاهوائية يؤدي الي حدوث التعب ولذلك فإن الاستشفاء الكامل من التعب يعني تخلص الجسم من هذا الحامض الزائد في العضلات وفي الدم ،ومن العوامل التي تزيد من سرعة التخلص من حامض اللاكتيك اداء تمرينات بدنية خفيفة خلال فترة الاستشفاء وتسمي هذه التمرينات بتمرينات التهدئة ( 26 : 192 )

وبذلك يعتبر حامض اللاكتيلك احد الاسباب الرئيسية التي تسبب الاجهاد البدني ويرتبط ذلك بظاهرة التعب ، ولذلك فإن قياس لاكتات الدم اثثاء الراحة والمجهود يمثل مؤشرا هاما يعبر عن الاجهاد نظرا لان مستوي لاكتات الدم هو المؤشر الجيد لتحمل الاداء ولان استجابة لاكتات الدم للتدريب حساسة جدا فإن برامج التدريب تحتاج الي تخطيط اكثر تخصصا و ارتباطا بإستجابة لاكتات الدم (10 : 89 )

وتظهر علامات التعب في رياضة الجودو في اشكال مختلفة كزيادة زمن اداء الصراع عاليا ( ناجي وازا ) او عند اداء دهارات اللعب الارضي ( كتامي وازا ) مما ينعكس في قدرة اللاعب علي إخراج القوة الانفجارية او الاداء بالقوة والسرعة المناسبة للاداء المهاري ( 31 : 129 )

ويري "عحم حامد شداد" (2009م) ،"ياسر عبد الرؤف" (2005م) ان رياضة الجودو تحقق التتمية البدنية والعقلية من خلال عمليات التعليم والتدريب للوصول بلاعب الجودو الي اعلي مستوي من الاداء الفني عن طريق الارتقاء بالاجزة العضلية والعصبية بوجه عام ،ويعتبر اكتساب لاعب الجودو للعناصر البدنية الخاصة شرط اساسي لاتقان المهارات الحركية ،ولذلك يعتبر الاعداد البدني الخاص والاعداد المهاري وجهان لعملة واحدة ويعملان علي تطوير اداء اللاعب وتزويده بالاداء الفني اللازم مما يؤدي الي زيادة قدرة اللاعب علي التكيف للاوضاع المتغيرة اثناء الاداء بصورة فعالة (24 : 31 ) ( 35 : 167 )

ويتقق كلا من "ريسان خربيط ، ابو العلا عبدالفتاح" (2016م) و "ياسر يوسف" (2005م) بان التحمل الخاص من اهم العناصر اللازمة لممارسة رياضة الجودو فهو عنصر ضروري لاستكمال منطلبات اللاعب فهو يزيد قدرة اللاعب في التغلب علي مقاومات ذات شدة تتراوح مابين الثدة الاقل من القصوي الي الثدة 
المتوسطة ومواجهة المقاومات اثثاء الاداء لقترة طويلة نسبيا ،وهو مايتناسب مع الرياضات التي يتراوح زمن الاداء فيها مابين (2 - 5 ) دقائق لذا فإن عنصر التحمل مع اللعب بالقوة والسرعة عنصر اساسي يجب علي اللاعب والمدرب الاهتمام به ووضعه بشكل اساسي في البرنامج التدريبي للاعبين بالاضافة الي كافة العناصر البننية والمهارية الخاصة باللعبة ( 9 : 74 ) ( 35 : 102 )

وقد لاحظت الباحثة ان رياضة الجودو تتطلب كثير من الجهذ نطرا لتعدد مهاراتها ولضمان الية الاداء المهاري حتي يستطيع اللاعب اداء الهجوم او الدفاع ومواجهة معظم مواقف اللعب المتغيرة حيث يستخدم اللاعب كل امكانياته وقدرته وقوته عند اداء المهارة المختارة وفقا للموقف التنافسي ، كما تري ان المتغيرات الفسيولوجية هي الاساس الذي يقوم عليه التقدم بمستوي الاداء والانجاز لدي لاعب رياضة الجودو ونظرا لارتباطها بالاعداد البدني والمهاري والخططيولكي يستطيع لاعب الجودو تنفيذ المهارات الفنية بكفاءة عالية اثناء المباراة التي تمتد الي اربعة دقائق وتحت ضغط المنافسة وارتفاع مستوي المقاومة لتنفيذ المهارات والحركات المركبة من حيث السرعة وقوة التتفيذ مع انسيابية الاداء والاقتصاد في الجهر ،الامر الذي يؤدي الي ضرورة الاهتمام بتحسين المتغيرات الفسيولوجية (التعب العضلي) بالقدر الكافي الذي يضمن للاعب تنفيذ المهارات اثثاء الاداء بفاعلية عالية لذا حاولت الباحثة ان تتناول بالدراسة موضوع الاجهاد البدني المرتبط بمعدل تتمية التحمل الخاص كجانب هام في الاداء الحركي لرياضة الجودو وذللك من خلال تدريبات كروس فيت والتي قد يكون لها تأثير علي زيادة قدرة اللاعب علي تحمل الاجهاد البدني في ظروف الاداء الدختلفة مع تحسين مستوي اداء فنون الصراع عاليا (ناجي وازا) حيث انها تعد من التدريبات التي تتميز بإحتوائها علي حركات متتوعة بجانب انها تعمل في مستويات مختلفة ( الافقي - السهمي- المستعرض ) مما يساعد علي تحسين اللياقة البدنية التي بدورها تساعد علي تحسين مستوي الاداء المهاري والتكنيك

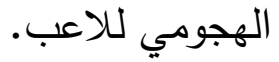


يهدف البحث الي معرفة تأثير تدريبات كروس فيت لمرحلة السنية للناشئين تحت 13 سنة علي : 1. الجهد البدني المتمثل في (معدل حامض اللاكتيك في الدم اثناء الراحةمعدلحامضاللاكتيكفيالدمبعدالمجهود) 2. التحمل الخاص المتمثل في (تحمل الاداء-تحمل القوة - تحمل السرعة). 3. بعض مهارات التكنيك الهجومي المتمثلة في

(او اتش جاري + تاني اتوشي -تاي اتوشي + او اتش جاري -اتش ماتا + او اتش جاري -ـش ماتا + كو اتش جاري - هراي جوشي + او سوتو جاري - تسوري كومي جوشي + او اتش جاري - هيزا جورما + هراي جوشي ) فروض البحث

1. توجد فروق دالة احصائيا بين القياسين القبلي والبعدي لهتغيرات الجهد البدني (قيد البحث) لصالح القياس البعدي.

2. توجد فروق دالة احصائيا بين القياسين القبلي والبعدي لمتغيرات التحمل الخاص (قيد البحث) لصالح

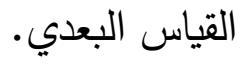

3. توجد فروق دالة احصائيا بين القياسين القبلي والبعدي في بعض مهارات التكتيك الهجومي ( قيد البحث ) لصالح القياس البعدي. 4. توجد علاقة ارتباطية موجبة بين متغيرات الجهد البدني والتحمل الخاص والتكنيك الهجومي لمهارات

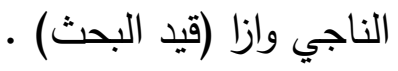




\section{مصطلحات البحث}

\section{تدريبات كروس فيتCrossfit Traning}

هي تدريبات يستخدم فيها وزن الجسم ضد الجاذبية لبناء وتطوير القوة والتوازن والمرونة والقدرة العضلية والرشاقة وتحمل القوة وتعتمد في ادائها علي عضلات البطن والظهر ويمكن للجميع ممارستها باختلاف السن والجنس والحالة البدنية للممارسين (46 : 20)

Anearobic poweriالقدرة اللاهوائية

هي عبارة عن خليط من تمارين الايروبكس وتمارين وزن الجسم ، وتمارين باتيل روب وتمارين بليو سوفت بوكس وتدريبات لياقة بدنية وبناء عضلات ، وتركز هذه التدريبات علي المرونة والرشاقة والقوة والتحمل والتنفس الصحيح (47)

\section{الجهر البذني Physical Activity}

هو الحالة التي يصل اليها الرياضي بعد اداء اقصي مجهود بدني ولا يستطيع الاستمرار في الاداء. $(30: 76$

\section{تحمل الاداء Performance Endurance}

هو الاستمرار في الاداء الحركي وذلك خلال فترة زمتية محددة مستخدما العمل العضلي باقصي مجهود (تعريف إجرائي)

Speed Endurance تحمل السرعة

هو القدرة علي مقاومة التعب عند اداء الاحمال بدرجة سرعة تبدأ من قبل القصوي حتي السرعة القصوي 
Muscular Endurance تحمل القوة

هو المقدرة العضلية علي الاستمرار في الاداء خلال فترة زمنية محدة ويرتبط بإعادة مخرجات حمل التدريب الخاصة بالقوة والتحمل معا (19)

\section{OffenderTechnique التكنيك الهجومي}

هو اسلوب يقوم به التوري بإختيار مهارة من مهارات الناجي وازا للحصول علي الايبون وذلك تبعا لمواقف المنافسة (تعريف إجرائي)

Nage - Waza مهارات الناجي وازا

هي مهارات الرمي من الوقوف سواء باليدين او الرجلين او الوسطويتم اختيار لاعب الجودو لها بناء علي المسافة بينه وبين منافسه ومركز ثقله وقاعدة ارتكازه من منافسه (20)

الاراسات السابقة

( 1 ) قام "محم صابر شفيق"(2013 ) (25) بدراسة تهذف الي التعرف علي تاثير تدريبات بعض القدرات البدنية الخاصة علي فاعلية الاداء المهاري والخططي لناشئ الكاراتيه وقد استخدم اللاعب المنهج التجريبي لمجموعتين ضابطة وتجريبية قوام كلا منهما 20 لاعب من نادي المنصورة الرياضي وكانت اهم النتائج تفوق المجموعة التجريبية علي المجموعة الضابطة في القدرات البدنية الخاصة ومستوي الاداء المهاري والخططي كما اثر البرنامج ايجابيا علي فاعلية اداء المهارات الهجومية والهجومية المضادة والدفاعية.

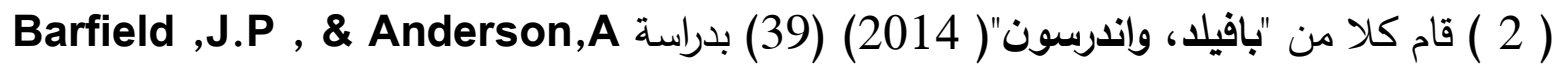
تهذف الي معرفة تاثير تدريبات كروس فيت علي اللياقة البدنية المرتبطة بالصحة واستخدما المنهج التجريبي لمدة 12 اسبوع علي عينة قوامها 50 لاعب تم تقسيمها لمجموعتين احداهما تجريبية والاخري ضابطة قوام كلا منهما 25 لاعب وكانت اهم النتائج وجود فروق دالة احصائيا لصالح المجموعة التجريبية في متغيرات القدرة الهوائية والتحمل العضلي 
( 3 ) قام "جوينز ،جوستين مايكل"( 2014) (45) بدراسة تهف الي Goins , Justin Michael

التعرف علي التاثيرات الفسيولوجية لتتريبات كروس فيت باستخدام المنهج التجريبي علي عينة قوامها 12

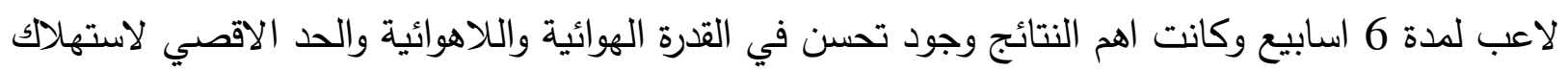
الاكسجين وضغط الدم الانبساطي ومستوي انظمة الطاقة لعينة البحث

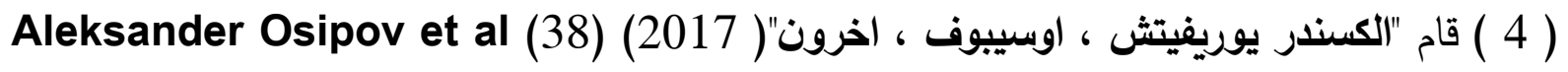

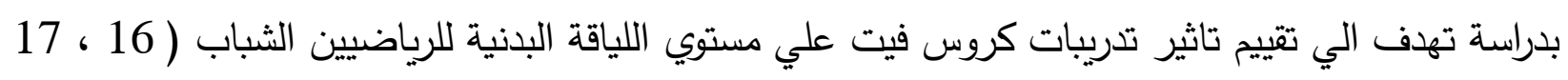

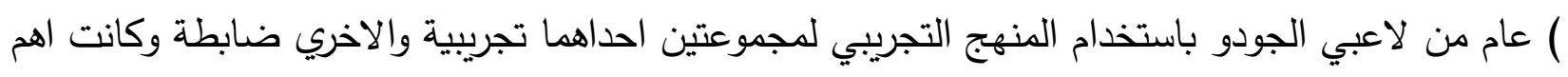

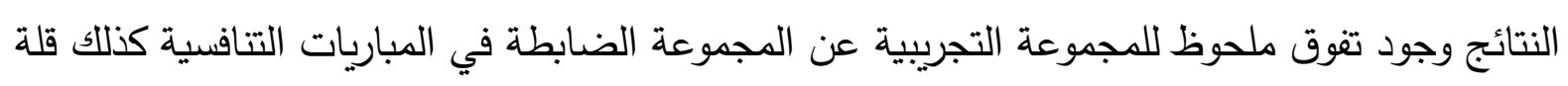
تركيزات لاكتات الدم للمجموعة التجريبية عن المجموعة الضابطة

( 5 ) قام "احمد حرب ابو زايدة"( 2018) (3) بدراسة تهدف الي التعرف علي تاثير استخام التنريب

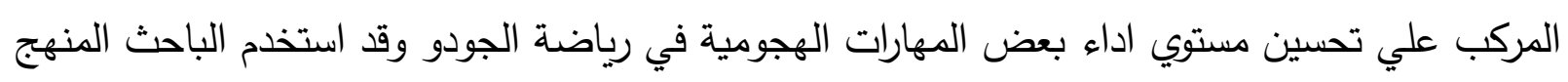

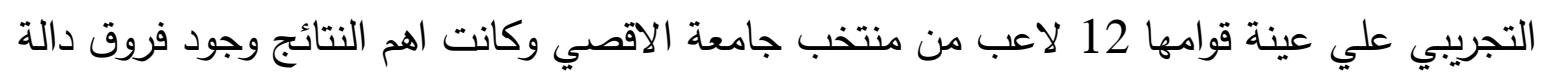
احصائيا لصالح القياس البعدي في المهارات الهجومية للاعبين

( 6 ) قام "طه احمد محم بدوي"( 2018) (14) بدراسة تهدف الي تصميم برتامج تدريبي باستخدام مجموعة تدريبات كروس فيت ومعرفة تاثيرها علي بعض الدتغيرات البنية وفاعلية الاداء الفني للاعبي الكومتيه

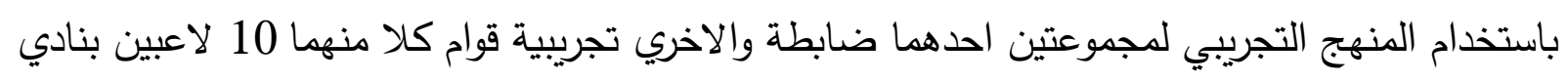
ملوي الرياضي بمحافظة المنيا وكانت اهم النتائج تحسن سرعة رد الفعل المركبة وسرعة الاداء والتوافق

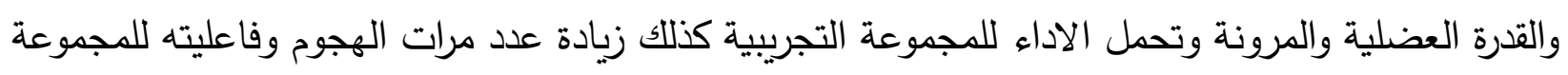
التجريبية التي استخدت تدريبات كروس فيت عن المجموعة الضابطة التي اتبعت البرنامج التتريبي التقليدي 


\section{إجراءات البحث : منهج البحث:}

استخدت الباحثة المنهج التجريبي باستخدام التصميم التجريبي لمجموعهواحدة تجريبية وذللك لمناسبتها لطبيعة هذه الدراسة

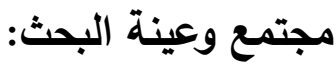

تم اختيار مجتمع وعينة البحث بالطريقة العدية من لاعبي نادى الثرقية الرياضي بالزقازيق للناشئين (تحت 13 سنة) للموسم الرياضي 2019 / 2020 واشتمل المجتمع على (34) لاعب ،تم استبعاد (4) لاعبين لعدم الانتظام في التدريب ،ثم تم سحب (8) لاعبين للعينة الاستطلاعية، ليصبح قوام عينة البحث الأساسية (22) لاعب، طبق عليهم برنامجتريبات كروس فيت، وقد قامت الباحثة بإجراء التجانس لعينة البحث الفعلية وجدول (1)يوضح ذللك

\section{شروط اختيار عينة البحث}

• يكون الناشئ مسجل في الاتحاد المصري للجودو • يكون حاصل علي الحزام الازرق علي الاقل • يكون منتظم في التدريب • الا يقل العمر التدريبي للاعب عن 4 سنوات 
جدول(1)

المتوسطات الحسابية والانحرافات المعيلية واللوسيط ومعاملات الالتواء

للمتغيرات قيد البحث(تجانس المجتمع)

ن

\begin{tabular}{|c|c|c|c|c|c|c|}
\hline الالتواء معامل & الوسيط & الانحراف & المتوسط & وحدة القياس & المتغيرات & \\
\hline $0,15^{-}$ & 13 & 0,76 & 12,96 & سنة & 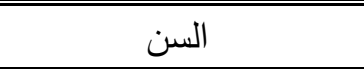 & \multirow{4}{*}{ الأساسية } \\
\hline 0,47 & 157 & 1,65 & 157,26 & سم & 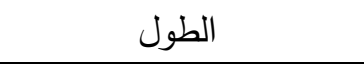 & \\
\hline $0,07-$ & 55 & 2,77 & 54,93 & 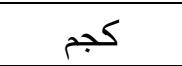 & 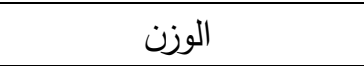 & \\
\hline 2,58 & 3 & 0,50 & 3,43 & سنة & العمر التدربيى & \\
\hline 0,35 & 1,65 & 0,17 & 1,67 & ملمي مول / & حامض اللاكتيك قبل & \multirow{2}{*}{ 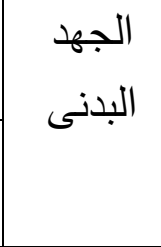 } \\
\hline 0,39 & 11 & 1,75 & 11,23 & ملي مول / لتر & حامض اللاكتيك بعد & \\
\hline $0,09-$ & 17 & 1,21 & 16,96 & عدد & تحمل آداء & \multirow{3}{*}{ البنتيرات } \\
\hline 0,68 & 7 & 1,75 & 7,40 & عدد & تحمل السرعة & \\
\hline $0,47-$ & 12 & 1,52 & 11,76 & ثانية & تحملالقوة & \\
\hline 1,13 & 6 & 1,06 & 6,40 & درجة & اتش ماتا +اواش جارى & \multirow{8}{*}{ المهارية المغيرات } \\
\hline 1,28 & 6 & 1,006 & 6,43 & درجة & اتش ماتا +كواتش جارى & \\
\hline 0,43 & 6 & 1,37 & 6,20 & درجة & هراى جوشي+ اوسوتو جارى & \\
\hline $0,34-$ & 7 & 1,22 & 6,86 & درجة & تسوريكومى جوشي+ او انش & \\
\hline 0,11 & 7 & 0,76 & 7,03 & درجة & هيزا جورحا + هراى جوشى & \\
\hline $0,60^{-}$ & 7 & 0,99 & 6,80 & درجة & هيزاجورما + اوسوتو جارى & \\
\hline 0,17 & 7 & 1,04 & 7,06 & درجة & اوسوتوجارى + هيزا جورما & \\
\hline $0.11^{-}$ & 6,50 & 1,008 & 6,46 & درجة & دى آشى هراى + هيزا جورما & \\
\hline
\end{tabular}

يتضح من الجدول (1) أن معاملات الالتواء تراوحت ما بين (-0.07 ، 20.58)أى جميع القياسات قيد البحث

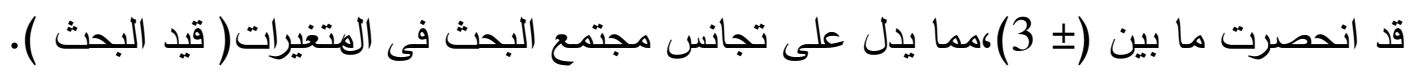


وسائل جمع البيانات:

قامت الباحثة بجمع المعلومات والبيانات عن طريق المسح المرجعي للمراجع العلمية والبحوث السابقة والمشابها لموضوع البحث

\section{أولا-الأجهزة والأدوات المستخدمة في البحث: ( مرفق 7 ، 8 )}

جهاز اكوسبورتAccutrend Lactate لقياس معرل حامض اللاكتيك في الدم

• جهاز الرستاميتر لقياس الطول بالسنتيمتر ووزن الجسم بالكيلو جرام.

ساعة إيقاف.

شريط قياس.

• • • احبال اثقال Battle Rope (باتيل روب).

• إستب مرن متعدد الارتفاع Plyo Soft Box (بليو سوفت بوكس).

بساط ارضيiTatami.

ثانيا-الاختبارات البذنية: مرفق (3)

قامت الباحثة بالاطلاع على العديد من المراجع العلمية المتخصصة فى مجال الجودو لتحديد المتغيرات والاختبارات البدنية (قيد البحث) وقد أسفر ذلك عن تحديد المتغيرات البدنية والاختبارات وهي كالتالي:

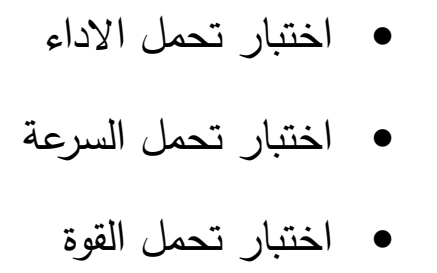

ثالثا- التكتيكالهجومي لمهارات الناجي وازا

وذللك من خلال لجنة مكونة من ثلاث حكام من منطقة الثرقية للجودو ممن لهم خبرة لا تقل عن (10) سنوات في مجال التحكيم ( مرفق 2 ) عن طريق استمارة خاصة بكل لاعب ( مرفق 4 ) وضمانا لتحقيق الموضوعية وصدق القياس تم تقييم اللاعبين باستخدام اللجنة في القياسين القبلي والبعدي وكانت درجة التقييم (10) درجات لكل مهارة واخذ متوسط الدرجة للمحكمين الثلاثة . 


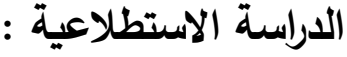

قامت الباحثة بإجراء الدراسة الاستطلاعية في الفترة من السبت2019/8/17م الى السبت2019/8/24م على عينة قوامها (8) لاعبين تم اختيارهم بالطريقة العشوائية من مجتمع البحث وخارج عينة البحث الأساسية، وقد هدفت الدراسة الاستطلاعية إلى ما يلي:

$$
\begin{aligned}
& \text { • إيجادالمعاملاتالعلمية(صدق - ثبات) الاختباراتقيدالبحث. } \\
& \text { • التأكدمنصلاحية الأدواتوالأجزةةالمستخدمة. } \\
& \text { التعرفعلمديمناسبة|لاختباراتالمستخدمةلعينةالبحث. } \\
& \text { • التعرفعلمديملائمةمحتوبالبرنامجالمقترحلعينة|لبحث. } \\
& \text { التعرفعلدالصعوباتالتيقدتواجهالباحثة|أثناءتطبيقالبرنامج. } \\
& \text { مناسبتزمنالوحدةالتدريبيةفالبرنامجالمقترح. } \\
& \text { المعاملات العلمية لاختبارات (قيد البحث) : }
\end{aligned}
$$

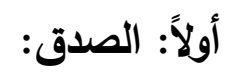

تم حساب صدق المتغيرات البدنية والمهارية قيد البحث عن طريق صدق (التمايز) على مجموعتين متساويتين فى العدد قوام كل مجموعة منهن (8) ناشئ، أحدهما تمثل عينة البحث الإستطلاعية (الهجموعة

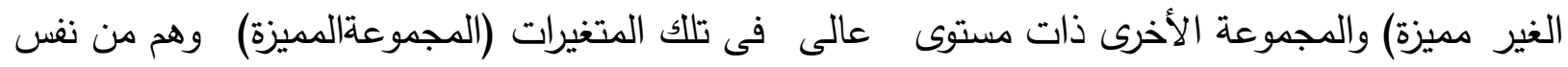
المرحلة السنية ولكن رتبتهم اعلي في الحزام والجدول رقم (2) يوضح ذللك. 
جدول (2)

دلالة الفروق بين المجموعتين المميزة وغير المميزة في المتغيرات قيد البحث

$8=2 ن=1$ ن

\begin{tabular}{|c|c|c|c|c|c|c|c|c|}
\hline \multirow{2}{*}{$\begin{array}{c}\text { sig الاحتمال } \\
\text { (p.value) }\end{array}$} & \multirow{2}{*}{ قيمة (z) من اخبار مان } & \multicolumn{2}{|c|}{ متوسط الرتب } & \multirow{2}{*}{ 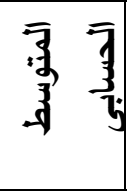 } & \multirow{2}{*}{$\begin{array}{ll}\overline{3} & \overline{7} \\
3 & 3 \\
\end{array}$} & \multirow{2}{*}{ القياس } & \multirow[b]{2}{*}{ المتغيرات } & \multirow{4}{*}{ 弐 } \\
\hline & & (2) & (1) & & & & & \\
\hline 0,005 & $2,838-$ & 11,81 & 5,19 & 19,25 & 17,12 & عدد & تحمل آداء & \\
\hline 0,008 & $2,626^{-}$ & 11,50 & 5,50 & 8,25 & 6 & عدد & تحمل السرعة & \\
\hline 0,001 & $3,205^{-}$ & 4,75 & 12,25 & 10 & 12,62 & ثانية & تحملالقوة & \\
\hline 0,004 & $2,844-$ & 11,81 & 5,19 & 8,12 & 6,25 & درجة & اتش ماتا +اواتش & \\
\hline 0,001 & $3,203-$ & 12,13 & 4,88 & 8,75 & 7,25 & درجة & اتش ماتا +كواتش & \\
\hline 0,005 & $2,804-$ & 11,75 & 5,25 & 8,37 & 6,12 & درجة & هاوتى جوتشب+ & \\
\hline 0,004 & $2,919-$ & 11,63 & 5,38 & 9,12 & 7,87 & درجة & جوشي+ تسويكومى اون & \\
\hline 0,004 & $2,902-$ & 11,75 & 5,25 & 8,62 & 7,25 & درجة & هيزا جورحا + هراى & 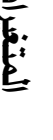 \\
\hline 0,003 & $2,938-$ & 11,81 & 5,19 & 9 & 7,50 & درجة & هيزاجورما + اوسوتو جارى & \\
\hline 0 & $2,970^{-}$ & 12,50 & 4,50 & 9,25 & 7 & درجة & اوسوتوجارى + هيزا & \\
\hline 0,001 & $3,369-$ & 12,38 & 4,63 & 8,75 & 6,25 & درجة & دي آشى هراي & \\
\hline
\end{tabular}

داله إحصائيا عند مستوى معنوية > 0.05

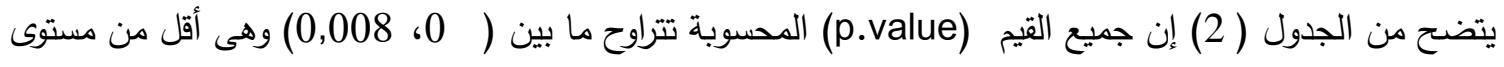

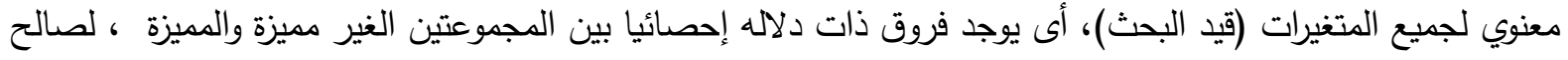
القياس المجموعة المميزة 


\section{ثانياً:- ثبات الاختبارات قيد البحث:-}

تم حساب معامل الثبات بطريقة تطبيق الاختبار وإعادة تطبيقه علمالصعينالاستطلاعية وقوامها (8)

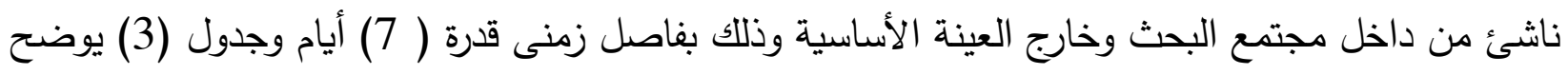

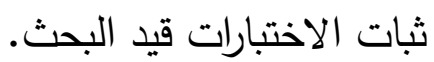
جدول (3)

معامل الارتبارط بين التطبيق الأول والثاني على ثبات الاختبارات (قيد البحث) للعينة الاستطلاعية

$8=\dot{0}$

\begin{tabular}{|c|c|c|c|c|c|c|c|}
\hline \multirow[t]{2}{*}{ قيمة (ر) } & \multicolumn{2}{|c|}{ إعادة التطبيق } & \multicolumn{2}{|c|}{ التطبيق الأول } & \multirow{2}{*}{ وحدة } & \multirow{2}{*}{\multicolumn{2}{|c|}{ المتغيرات }} \\
\hline & $\varepsilon$ & 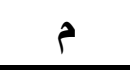 & $\varepsilon$ & b & & & \\
\hline$* 0,959$ & 1,16 & 17,25 & 1,24 & 17,12 & عدد & تحمل آداء & \\
\hline$* 0,953$ & 0,99 & 6,12 & 0,75 & 6 & عدد & تحمل السرعة & 承 \\
\hline *0,911 & 1,68 & 12,37 & 1,40 & 12,62 & ثانية & تحملالقوة & $\frac{3}{3}: \frac{3}{3}$ \\
\hline$* 0,943$ & 1,06 & 6,37 & 1,03 & 6,25 & درجة & اتش ماتا +|واش جارى & \\
\hline$* 0,882$ & 0,74 & 7,37 & 0,70 & 7,25 & درجة & جاتش ماتا +كواتش & \\
\hline$* 0,979$ & 1,48 & 6,25 & 1,64 & 6,12 & درجة & هراى جوشي|+ اوسوتو & \\
\hline$* 0,953$ & 0,75 & 8 & 0,99 & 7,87 & درجة & تسوريكومى جوشي|+ او & $\frac{2 L^{2}}{\$}$ \\
\hline *0,924 & 0,91 & 7,73 & 0,88 & 7,25 & درجة & هيزا جورج| + هراى & $\underline{E}$ \\
\hline$* 0,946$ & 1,06 & 6,62 & 0,92 & 7,50 & درجة & هيزاجورما + اوسوتو & $\underline{E}$ \\
\hline$* 0,906$ & 0,83 & 7,12 & 0,75 & 7 & درجة & اوسوتوجارى + هيزا & \\
\hline$* 0,924$ & 0,91 & 6,37 & 0,35 & 6,25 & درجة & دى آشى هراى + هيزا & \\
\hline
\end{tabular}


ويتضح من الجدول ( 3) وجود علاقة أرتباطية دالة إحصائياً عند مستوى معنوية 0.050 حيث تراوحت معامل الثبات ما بين ( 0,882: 0,979) ، مما يدل على ثبات اختبارات قيد البحث.

برنامج تدريبات كروس فيتCrossfit Training المقترح: مرفق (5)

قامت الباحثة بوضع برنامج لتدريبات كروس فيت، وذلك بعد إجراء مسح مرجعي للمراجع العلمية التي أمكن الحصول عليها ، والاطلاع على شبكة المعلومات ومشاهدة الفيديوهات الخاصة بهذه التدريبات ورأي السادة

الخبراء في مجال التدريب و المنازلات مرفق ( 1 )

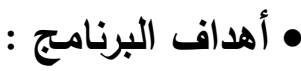

يهدف برنامج تدريبات كروس فيت إلى تحسين معدل حامض اللاكتيك اثثاء الراحة وبعد المجهود ، وتحسين التحمل الخاصالذي يشمل (تحمل الاداء -تحمل السرعة- تحمل القوة) وتحسين التكتيك الهجوميليعض مهارات الناجي وازا.

\section{• الإطار العام لتنفيذ البرنامج :}

تم تتفيذ البرنامج المقترح خلال ثلاث شهور (12) اسبوع بواقع (3) وحدات تدريبية في الأسبوع وزمن الوحدة التتريبية يتراوح ما بين (80 -95) دقيقة، حيث تشتمل كل وحدة على :

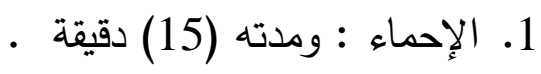

ويشتمل هذا الجزء على تدريبات الإحماء بهدف إعداد وتهيئة أجهزة وعضلات الجسم لتحمل أعباء الحمل خلال الجزء الرئيسي • 2. الجزءالرئيسى:

ويشتمل على تدريبات كروس فيت ومدتها ( 40: 50) دقيقة وتتضمن تمرينات باتل روب وتمرينات

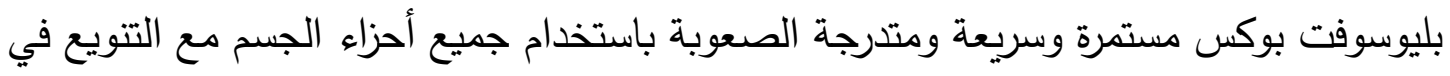
التمرينات، التدريب التكانكي على المهارات الهجومية ومدتها من (20 : 25) دقيقة.

$$
\text { 3. التهدئة: ومدتها (5) دقائق }
$$

وهو عبارة عن تمرينات استرخاء وتهيئة بالإضافة إلى تدريبات تتظيم التتفس وذلك للرجوع بأجهزة وعضلات الجسم إلى حالتها الطبيعية ، وتم تنفيذ البرنامج في الفترة الصباحية دون المساس بالبرنامج المتبع في النادي بخلاف التعرف على الاحمال لتشكيل حمل البرنامج 
تم تحديد الزمن الكلى للتنريب خلال البرنامج المقترح كالتالي :

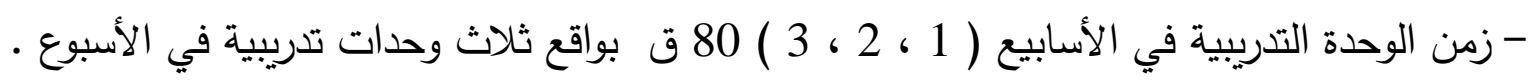

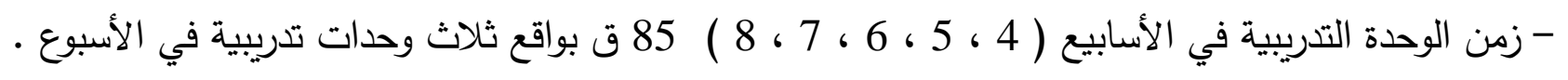

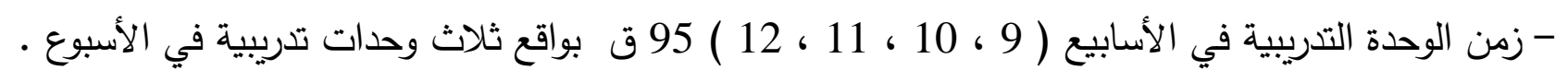

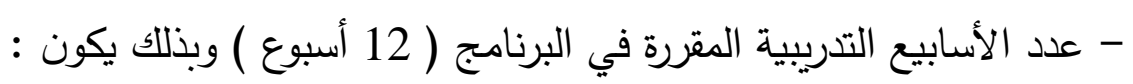

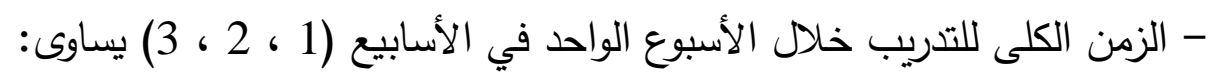
80

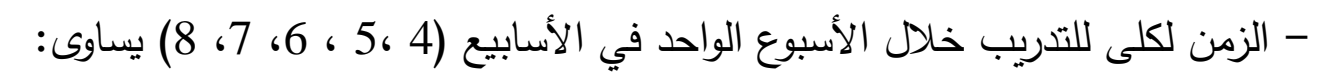
85 × 35 ق 355

- الزمن الكلى للتدريب خلال الأسبوع الواحد في الأسابيع (9 ، 10، 11 × 11، 12) يساوى:

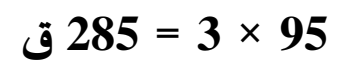

- إذا الزمن الكلى للتدريب خلال الأسابيع (1، 2، 3) يساوى: ق $720=3 \times 240$

- إذا الزمن الكلى للتدريب خلال الأسابيع (4، 5، 6، 7، 8 6 يساوى: ق 255

- إذاً الزمن الكلى للتدريب خلال الأسابيع (9، 10، 11، 120 × 11 يساوى: 285

- إذاً الزمن الكلى للتدريب خـلال فترة البرنامج التدريبي المقترح يساوى: ق 3135 = 1140 + 1275

• حمل التريب في البرنامج: ( مرفق 6 )

بعد الاطلاع على العديد من الأبحاث والمراجع العلمية ووفقاً لآراء السادة الخبراء قامت الباحثة بالتدرج في درجة الحمل داخل الوحدات التدريبية في البرنامج الابدات ولعراجع وتم تحديد شدة الحمل المناسبة وهى من 60\% الى 85\% من أقصى شدة 


\section{تحديد المتغيرات الأساسية للبرنامج :

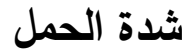

ويشير وائل الأسيوطى (2005م) نقلا عن فوران Foran (2003م) إلى أن تدريبات الأثقال والإستب

يجب أن تتدرج فى شدتها من الخفيف إلى المتوسط ثم العالى وذلك للوصول لأفضل مستوى من الأداء، وحددت الباحثة أنسب شدة للحمل التدريبى عند البداية لـ 60\% من أقصى ما يتحمله اللاعب. (34 : 72)

حجم الحمل

يتقق كلا من أبوالعلا عبدالفتاح وأحمد نصر الدين ( 2003م) (1) على أن حجم تدريبات الإستب

والأثقال يجب أن يتراوح مابين [ 6 : 15] تكرارات فى المجموعة الواحدة ، وأن تتراوح المجموعات مابين [ 6

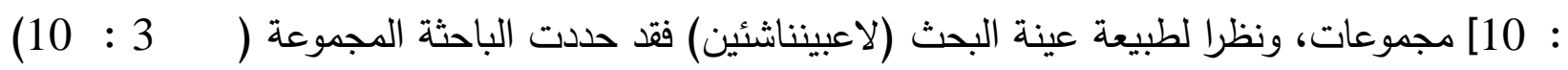
مجموعات. (116 (116) فترة الراحة بين المجموعات

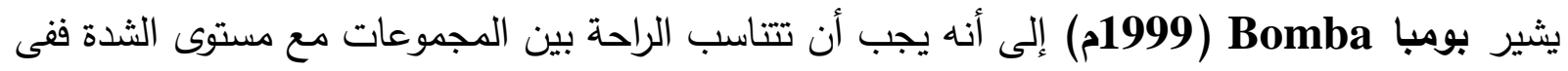
الثدة المنخفضة تتراوح من (1 : 2) ق والثدة المتوسطة (2 : 4) ق والقصوى (5 : 7) ق. (41 : 174) زمن البرنامج المقترح

يشير بيتشيل وإيريل Beachle \& Earle (2000م) إلى أن الددة المناسبة لبرنامج التدريب

$$
\begin{aligned}
& \text { بالإستب والأثقال مابين ( } 8 \text { ـ 12) أسبوع ليكون لها تأثير فعال. (40 : 435) } \\
& \text { خطوات تنفيذ التجربة: }
\end{aligned}
$$

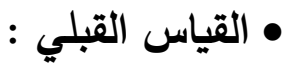

قامت الباحثة بإجراء القياس القبلي لمجموعة البحث في المتغيرات (قيد البحث) وذلك يومي الجمعة والسبت 23 ، 24اغسطس 2019م.

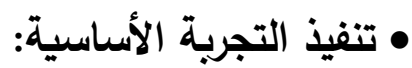

قامت الباحثة بتطبيق اليزنامج المقترح علي مجموعة البحث الاساسية ابتداء من يومالاحد2019/8/25م الى يومالخميس2019/11/14م ، على مدى (12) اسبوع بواقع (3) وحدات تدريبية في الاسبوع، واشتمل البرنامج على (36) وحدة تدريبية ، تحتوى كل وحدة على (الإحماء، والجزء الرئيسي الذى يشتمل عليتريبات 


$$
\begin{aligned}
& \text { كروس فيت والجزء المهارى، والتهئة في نهاية الوحدة) وتم التدريب ايام ( الاحد - الثلاثاء - الخميس) في } \\
& \text { الفترة الصباحية غير فترة تدريب الفريق. } \\
& \text { • القياس البعدي: }
\end{aligned}
$$

قامت الباحثة بإجراء القياس البعدي لمجموعة البحث في المتغيرات( قيد البحث) يوميإجمعة ، السبت15،16نوفمبر 2019م تحت نفس الظروف والشروط التي تم فيها القياس القبلي

\section{المعالجات الإحصائية:}

بناء على أهداف البحث وفروضه تم تحديد الأسلوب الإحصائي المستخدم لتحليل البيانات على النحو التالي

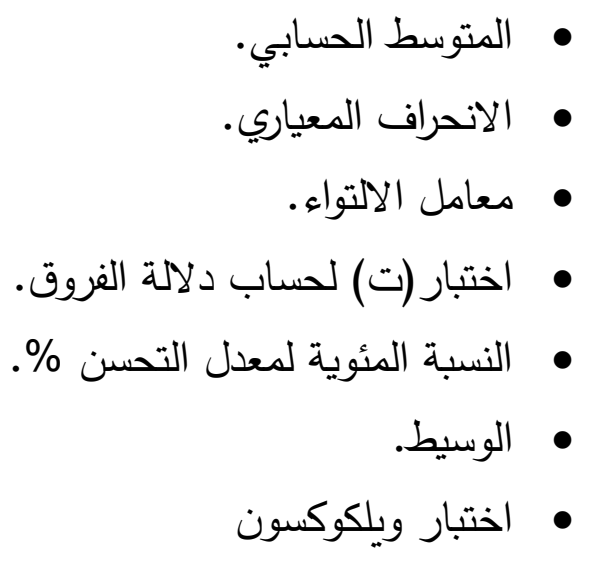


أولاً: عرض النتائج

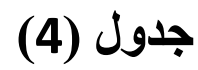

دلالة|الفروق بين القياسينالقبليوالبعديفيالمتغيرات(قيد البحث)

ن

\begin{tabular}{|c|c|c|c|c|c|c|c|}
\hline \multirow{2}{*}{ قيمة (تلالتها } & \multicolumn{2}{|c|}{ القياس البعدى } & \multicolumn{2}{|c|}{ القياس القبلى } & \multirow{2}{*}{ والقياس } & \multirow{2}{*}{\multicolumn{2}{|c|}{ المتغيرات }} \\
\hline & $\varepsilon$ & p & $\varepsilon$ & p & & & \\
\hline 4,176 & 0,19 & $\overline{11,49}$ & 0,16 & 1,70 & & حامض اللاكتيك قبل & $\bar{\ddagger}$ \\
\hline 5,545 & 1,46 & 9,36 & 1,76 & 11,50 & & حامض اللاكتيك بعد & $\overline{7}$ \\
\hline 6,397 & 1,84 & 19,77 & 1,23 & 16,90 & عدد & تحمل آداء & $\overline{3}$ \\
\hline 5,247 & 1,32 & 10,04 & 1,74 & 7,90 & عدد & تحمل السرعة & 繁 \\
\hline 4,405 & 1,26 & 9,90 & 1,47 & 11,45 & تانية & تحملالقوة & \\
\hline 6,724 & 0,95 & 8,81 & 1,10 & 6,45 & درجة & اتش ماتا +او اش & 尔 \\
\hline 4,743 & 1,73 & 8,36 & 0,94 & 6,13 & درجة & اتش ماتا +كو اتش & \\
\hline 4,796 & 1,39 & 8,31 & 1,30 & 6,22 & درجة & هراى جوتش+ اوسوتو جارى & \\
\hline 5,397 & 0,73 & 8,40 & 1,10 & 6,50 & درجة & تسوريكومى جوش اوش & $\sum^{2}$ \\
\hline 5,661 & 1,25 & 8,63 & 0,72 & 6,95 & درجة & هيز ا جورحا + هر اى & E: \\
\hline 7,108 & 1,10 & 8,90 & 0,91 & 6,54 & درجة & هيز اجورما + اوسوتو & E. \\
\hline 4,695 & 1,42 & 8,86 & 1,15 & 7,09 & درجة & اوسوتوجارى + هيز & \\
\hline 5,550 & 0,91 & 8,54 & 1,01 & 6,54 & درجة & دى آنى هراى + هيز & \\
\hline
\end{tabular}

يتضح من جدول (4) وجود فروق ذات دلاله احصائية بين القياس القبلى و البعدى لصالح القياس البعدى فى المتغير ات قيد البحث. 
جدول (5)

نسب التحسن بين القياسين القبلى والبعدى فى المتغيرات(قيد البحث)

ن

\begin{tabular}{|c|c|c|c|c|c|}
\hline \multirow[t]{2}{*}{ نسبة التحسن \% } & القياس & القياس & \multirow{2}{*}{ والقياس } & \multicolumn{2}{|l|}{ المتغيرات } \\
\hline & r & م & & & \\
\hline$\% 14,09$ & 1,49 & 1,70 & & حامض اللاكتيك قبل المجهود & \multirow{2}{*}{$\overline{\bar{j}} \overline{\mathrm{g}}$} \\
\hline$\% 22,86-$ & 9,36 & 11,50 & & حامض اللاكتيك بعد المجهود & \\
\hline$\% 16,98$ & 19,77 & 16,90 & عدد ع & تحمل آداء & \multirow{3}{*}{ 事 } \\
\hline$\% 27,08$ & 10,04 & 7,90 & عدد & تحمل السرعة & \\
\hline$\% 65,94$ & 9,90 & 11,45 & ثانية & تحملالكوة & \\
\hline$\% 36,58$ & 8,81 & 6,45 & درجة & اتش ماتا +او اش جارى & \multirow{8}{*}{$\begin{array}{l}E^{2} \\
\underline{E} \\
\underline{E} \\
\underline{E}\end{array}$} \\
\hline$\% 36,37$ & 8,36 & 6,13 & درجة & اتش ماتا +كو اتش جارى & \\
\hline$\% 33,60$ & 8,31 & 6,22 & درجة & هر اى جوتش+ اوسوتو جارى & \\
\hline$\% 29,23$ & 8,40 & 6,50 & درجة & تسوريكومى جوش+ او انش & \\
\hline$\% 24,17$ & 8,63 & 6,95 & درجة & هيز ا جورحا + هراى جوشى & \\
\hline$\% 36,08$ & 8,90 & 6,54 & درجة & هيز اجورما + اوسوتو جارى & \\
\hline$\% 24,96$ & 8,86 & 7,09 & درجة & اوسوتوجارى + هيز ا جورما & \\
\hline$\% 30,58$ & 8,54 & 6,54 & درجة & دى آنشى هر اى + هيز ا جورما & \\
\hline
\end{tabular}

توجد نسب تحسن مختلفة بين القياسين القبلى و البعدى لصالح القياس البعدى فى المتغيرات (قيد البحث). 
تشير نتائج جدول (4) الي وجود فروق ذات دلالة احصائية بين القياسين القبلي والبعدي لعينة البحث في متغيرات الجهد البدني (قيد البحث) لصالح القياس البعدي ،وترجع الباحثة هذه الفروق بين القياسات الي نوعية التدريبات المؤداه في برنامج تدريبات كروس فيت باستخدام تمارين حرة وتمارين بليو سوفت بوكس متعدد الارتفاعات مما كان لها اثر ايجابي علي تحسين متغيرات الجهد البدني (قيد البحث) كما تري الباحثة ان هذا الاختلاف بين قياسات لاكتات الدم في حالة الراحة وبعد المجهود يرجع الي تاثير المجهود علي عمليات الايض اللازمة لامداد العضلات بالطاقة حيث يترتب علي زيادة المجهود العضلي زيادة في احتياج الجسم للطاقة وبالتالي عمليات التمثيل الغذائي وزيادة احتياج العضلات العاملة للاكسجين وعندما يكون الامداد بالاكسجين غير كافي لتلبية احتياجات العضلة يترتب علي ذللك زيادة في تراكم لاكتات

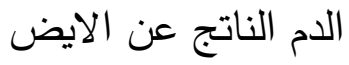

ويتقق ذلك مع ما اشار اليه "سعد كمال طه ، ابراهيم يحي خليل" 2004م (10) في ان ممارسة النشاط الرياضي يؤدي الي زيادة في انتاج لاكتات الام عندما يكون الامداد بالاكسجين غير كافي لتلبية متطلبات الطاقة وهذا يعني ان الزيادة في تركيز لاكتات الدم اثثاء النشاط الرياضي تعتبر مؤشر لتتمية الايض اللاهوائي ومع ثبات الحمل البدني يزداد تركيز لاكتات الدم طول فترة النشاط وقد يصل هذا التركيز الي عشرة اضعاف تركيزها اثناء الراحة

ويتقق ذلك مع ماتوصل اليه "ثريف محمد عادل شوقي" 2001م (11) ودراسة "محمود تحمد عبدالرحيم" 2001م (29) في ان مستوي لاكتات الدم يزداد بشكل ملحوظ بعد الاداء العضلي الذي يتسم بصفة التحمل كما تري الباحثة ان الاجهاد يمثل حالة من حالات التعب فعند اداء احمال تدريبية دون التخلص من التعب الناتج عنها فان ذلك يؤدي الي ظهور حالة الاجهاد بينما يعبر التعب عن الهبوط الوقتي في المقدرة علي الاستمرار في اداء العمل ويتمثل ذلك في رياضة الجودو عندما يحاول اللاعب (التوري) الهجوم باحدي مهارات رياضة الجودو ويخفق في احدي مراحل اداء المهارة مما يؤدي الي عدم تولد القوة اللازمة من المرحلة السابقة وعدم انسيابية الاداء للمرحلة الثانية في مواجهة مواقف اللعب المتغيرة باستمرار اثناء 
(الشياي) وعدم قدرته علي استغلال الهجمة الناقصة للتحول للهجوم المركب واستغلال ثغرات المنافس باداء الهجوم المضاد ،كما تري ان المتغيرات الفسيولوجية هي الاساس الذي يقوم عليه التقدم بمستوي الاداء والانجاز لاي لاعب رياضة الجودو

ويتفق ذلك مع نتائج دراسة "ايمان محما ابراهيم"2015م (4) ، "بسنت سعد الدين" 2008م (5) حيث يشيران الي ان استخدام التدريب المنظم باستخدام ادوات واثقال في التدريب سواء تدريبات المقاومة او تدريبات الحبال تؤدي الي زيادة دافعية اللاعبين نتيجة لاستخدام تدريبات متتوعة من حيث الثكل والاداء مما يؤدي الي تحقيق السيطرة التامة وتطوير مستوي الاداء المهاري

كما تشير نتائج جدول (5) الي ان هناك تحسن ونسب تغير مختلفة حيث كان تركيز لاكتات الدم قبل المجهود في القياس القبلي ( 1.7 ) وبعد المجهود ( 1.49 ) ونسبة التحسن ( 14.09 \% ) وهذا يعني ان هذا التكيف يرجع الي البرنامج الذي يشمل علي تدريبات كروس فيت والمبني علي اسس علمية ويتقق هذا مع الهدف من تطبيقه

كما تشير نتائج جدول (5) الي تحسن نسب تغير تركيز لاكتات الدم بعد المجهود ففي القياس القبلي ( 11.50 ) والقياس البعدي ( 9.36 ) ونسبة التحسن ( 22.86 \% ) وتعزو الباحثة هذا الاختلاف الي الاستمرار في اداء تدريبات كروس فيت والتي ترتبط ارتباطا وثيقا بالاجهاد البذني والذي ينعكس في شكل تكيف الجسم مع هذا النوع من الاداء ويظهر هذا التكيف في شكل انخفاض مستوي لاكتات الدم تحت تاثير المجهود

كما تري الباحثة ان مستوي التحسن في نسبة لاكتات الدم بعد المجهود يرجع الي ان تدريبات كروس فيت ذات الجهد البدني الاقصي ادت الي زيادة القدرة للمجموعات العضلية المختلفة مما ادي الي تحسن في نسبة تراكم حامض اللاكتيك بعد البرنامج مقارنة بنسبته قبل البرنامج حيث ان زيادة قدرة العضلات يسهم في زيادة قدرتها علي العمل وتحمل تراكم اللاكتيك اثناء العمل وايضا سرعة اكسدته بواسطة العضلات الغير مشتركة في الاداء بصورة مباشرة ،وكذللك تزداد كفاءة الجسم في سرعة التخلص من حامض اللاكتيك في فترات 
الراحة والاستشفاء ككما ان استخدام العمل اللاهوائي في الوحدة التدريبية يزيد كفاءة التدريب مما يترتب عليه انخفاض مستوي تركيز اللاكتيك في الدم

ويشير "بهاء الدين ابراهيم سلامة" 2008م الي ان مدة ساعة علي الاكثر تكون كافية للتخلص من حوالي 90\% من حامض اللاكتيك بعد التدريبات ذات الثدة القصوي بدنيا حيث يقل الزمن اللازم لذلك كلما قلت شدة التمرينات كما ان قيام الفرد ببعض تمرينات التهدئة الخفيفة يساعد علي التخلص منها ( 7 : 397 ) ويتقق ذلك مع نتائج دراسة كلا من "جوينز ،وستين مايكل" 2014 (45) في ان البرامج التدريبية باستخدام تدريبات عالية الثدة والحجم ادت الي انخفاض تركيز حامض اللاكتيك بعد المجهود

كما يتقق ذلك مع ما توصلت اليه "صفاء صالح" 2008م (13)، "محمود محمل عبد الرحيم" 2001 (29) الي ان البرامج التدريبة المقننة ادت الي تحسين مستوي تركيز لاكتات الدم وبالتالي قل الاجهاد البدني وبهذا يتحقق صحة الفرض الاول الذي ينص علي 'توجد فروق دالة احصائيا بين القياسين القبلي والبدي لكتغيرات الجها البذني (قيد البحث) لصالح القياس البعدي "

كما يتضح من جدول ( 4 ) وجود فروق دالة احصائيا بين القياسات القبلية والبعدية في متغيرات التحمل الخاص ( قيد البحث) لصالح القياس البعدي وتعزو الباحثة ذلك نتيجة لتطبيق تدريبات كروس فيت المقترحة والتي ادت الي تحسن في متغيرات التحمل الخاص ( تحمل الاداء ، تحمل السرعة ، تحمل القوة ) التي يحتاج اليها اللاعب وذللك لان طبيعة رياضة الجودو المليئة بالالتحام المباشر خلال زمن المباراة والتغير المفاجئ في اوضاع اللاعبين والتحرك علي البساط والمواقف المفاجئة التي قد تحدث خلال المباراة بين التغير من الهجوم للدفاع او من الدفاع للهجوم •

ويتفق ذلك مع "فايزة خضر" 2008 في ان لاعب الجودو يحتاج الي التحمل الخاص وذللك لضمان استمراره في بذل المجهود بسهولة ويسر اثناء المباراة التي قد تستمر ل 4 دقائق والتحمل يمثل نتيجة الترابط الدقيق من العزيمة والمهارة الالية وعمليات التوافق المستمر لاطول مدة ممكنة ولاكبر عدد من المرات وذلك لان المطلوب لمباريات الجودو هو استمرار الاداء الحركي بالسرعة والقوة المثلي لفترة زمنية محددة باستخدام العمل العضلي باقصي قدرة دون الهبوط في مستوي الاداء ( 21 : 77 ، 78 ) 
ويشير "بهاء الدين سلامة"( 2000 ) (6)الي ان التدريب المنتظم يؤدي الي زيادة كفاءة الجهاز العضلي ويظهر ذلك في قدرة العضلة علي انتاج القوة العضلية التي تزيد من سرعة انقباض العضلة بالاضافة الي تحسين صفة التحمل التي تعتمد بدورها علي كفاءة العضلات

ويتقق ذلك مع نتائج دراسات كلا من"محمود محمود السيد"( 2010) (28) و "احمد ابراهيم عزب" (2009) (2) و "رانيا محمد عبد الجواد"( 2006 ) (8)، "ثيرين احمد يوسف" ( 2005 ) (12) والتي اشارت الي وجود دلالة لزيادة التحمل العضلي نتيجة الممارسة المنتظمة ةالمستمرة في البرامج التدريبية المقننة حيث ان زيادة تحمل القوة تؤدي الي زيادة قدرة اللاعب علي تحمل التعب وبالتالي زيادة القدرة علي تحمل الاداء ويري "مراد ابراهيم طرفة" 2001 انه تظهر اهمية التحمل الخاص للاعب الجودو من خلال زيادة زمن المباراة في حالة التعادل او لعب اكثر من مباراة في يوم واحد فاللاعب المعد جيدا لا يشعر باي تعب عضلي سواء بالنسبة لعضلات الذراعين او الظهر او الرجلين نتيجة للجهد المبذول اثناء الصراع ( 22 : 44

ويتفق ذللك مع كلا من"يحي الصاوي" 1996 ، "ياسر يوسف" 2005 في ان تهيئة لاعب الجودو بدنيا وعقليا ونفسيا هي مكونات اللياقة الثاملة لمواجهة منطلبات الاداء واحد الركائز الرئيسية لعملية التدريب والتي تزيد من قدرته علي اداء العمل العضلي للوصول لاعلي مستوي مكن ( 36 : 98 ) ( 35 : 167 )

ويري "علي السعيد ريحان"(2007) (17) ان التواحي الفنية والبدنية والاعداد الوظيفي مظاهر مترابطة وتحسن مظهر واحد يؤدي الي تحسن كافة المظاهر الاخري فتحسين الاداء البدني يؤدي الي زيادة القدرة علي اداء المهارات وبذلك يتمكن اللاعب من تطوير الاعداد المهاري والفني والتكنيكي وذلك لخدمة هدف واحد هو تحقيق الفوز في المباراة

ويتضح ايضا من جدول ( 4 ) وجود فروق ذات دلالة احصائية بين القياسين القبلي والبعدي لعينة البحث في متغيرات التحمل الخاص قيد البحث لصالح القياس البعدي وتعزو الباحثة هذه الفروق الي البرنامج المتبع والذي يحتوي علي تدريبات خاصة ومشابهة للمسار الحركي لمهارات التكنيك الهجومي قيد البحث مما ساهم 
بطريقة مباشرة وملحوظة في الفروق بين القياسات القبلية والبعدية في تحمل الاداء وتحمل السرعة وتحمل القوة

كما تثير نتائج جدول (5) الي وجود نسب تحسن حيث كانت نسبة تحمل الاداء 16.98 \% وكانت نسبة تحسن تحمل السرعة 27.08 \% بينما كانت نسبة تحسن تحمل القوة 65.94 \%حيث ادت تدريبات كروس فيت الي رفع كفاءة نظم انتاج الطاقة مما ساعد علي قدرة العضلة علي مقاومة التعب مما ادي الي تحسن متغيرات التحمل الخاص (قيد البحث) وبذلك يتحقق الفرض الثاني الذي ينص علي 'توجد فروق دالة احصائيا بين القياسين القبلي والبعدي لمتغيرات التحمل الخاص (قيد البحث) لصالح القياس البعدي" يتضح من نتائج جدول ( 4 ) وجود فروق ذات دلالة احصائية بين القياسين القبلي والبعدي لعينة البحث في التكنيك الهجومي (قيد البحث) لصالح القياس البعدي وتعزو الباحثة هذا التحسن في مستوي اداء المهارات الهجومية المركبة (قيد البحث) الي تاثير تدريبات كروس فيت والتي تتثابه في ادائها وطبيعة العمل العضلي لها ومسارها الحركي مع المتطلبات البدنية والمهارية لمهارات الناجي وازا كما ان مكونات الوحدة التدريبية الخاصة بتدريبات كروس فيت قد صممت لتنمية مهارات الناجي وازا وزيادة التحمل والذي بدوره يؤدي الي تاخير ظهور التعب والاجهاد العضلي والبدني مما يؤدي الي تحسين مستوي الاداء المهاري ،كما ان البرنامج المقنن والمبني علي اسس علمية ادي الي تحسن واضح وترسيد عمليات انتاج الطاقة والذي ادي بدورة الي نقص انتاج الاكتات مما ترتب عليه تحسن كفاءة اللاعب ،وكذلك راعي البرنامج المقترح الفروق الفردية بين اللاعبين من حيث طريقة التدريب وشدة وحجم وكثافة التدريب

ويري "مراد ابراهيم طرفة" 2001م (22) ان التدريب في رياضة الجودو يعتمد علي الارتقاء بالمهارات المختلفة وذلك عن طريق التدريب بشكل دائم ،وكذللك فان الطاقة المبذولة من اللاعب تعمل جنبا الي حنب وبصورة منتظمة مع المستوي الفني حتي يستطيع اللاعب اداء مهاراتها بفاعلية

ويتقق ذللك مع كلا من "يحي الصاوي ، محمد حامد شداد ، ياسر عبد الرؤف "2005 و يحي الصاوي محمود 2000م و ان رياضة الجودو تتميز بتعدد مهاراتها وتتوعها سواء في اللعب من اعلي (ناجي وازا) او اللعب من اسفل (كتامي وازا) وكل هذه المهارات تؤدي باجزاء الجسم ( اليدين والوسط والرجلين ) سواء بشكل 
مباشر من خلال المباريات (الشياي) او بشكل غير مباشر اثثاء اداء الهجمات مما يؤدي الي صعوبة اختيار

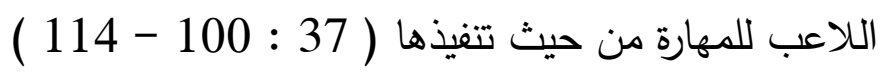

كما يتفق ذلك مع نتائج دراسات كلا من محم لبيب عبدالعزيز"( 2012) (27)و "هاني عادل مرسي"( 2004) (33)وجود تحسن ملحوظ بمستوي اداء اللاعبين في المهارات الحركية المركبة نتيجةلتحسن الصفات

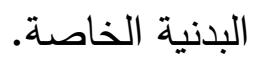

لذا تري الباحثة ضرورة الاهتمام بوضع تدريبات خاصة لنوع الانقباضات السائدة في مهارات الجودو المختلفة

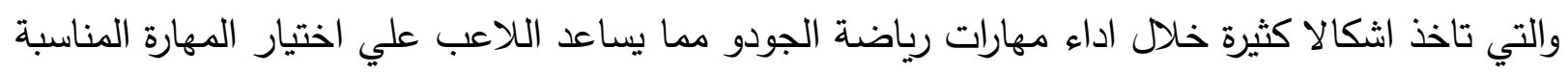
لمواقف اللعب المتغيرة مما يمكنه من تركيب المهارات الفنية في صورة جملة حركية انسيابية وبتوافق جيد الفيد وبما يتناسب مع مواقف اللعب الامر الذي يتطلب توافر قاعدة عريضة من المهارات الفنية والذي يتطلب بدوره قدرات بدنية خاصة تساعد علي اداء التكنيك الهجومي لهذه الههارات

ويتفق ذلك مع " عصام عبد الخالق" 2005 حيث اشار الي ان الاداء المهاري يرتبط بالقدرات البدنية الخاصة ارتباطا وثيقا حيث يعتمد اتقان الاداء المهاري علي مدي تطوير منطلبات هذا الاداء من قدرات

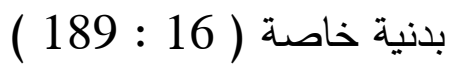

ويتفق ذلك مع دراسة كلا من "تيفين حسين( 2008) (32)، محم السيد معروف( 2008 ) (23)، صفاء صالح( 2008) (13) في ان البرامج التدريبية الدقننة تؤدي الي تحسين مستوي الاداء الدهاري والمتغيرات

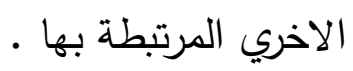

كما تثير نتائج جدول ( 5 ) الي وجود نسب تغير وتحسن في مستوي مهارات التكنيك الهجومي لدي لاعبي رياضة الجودو وهي (او اتش جاري + تاني اتوشي -تاي اتوشي + او اتش جاري -اتش ماتا + او اتش

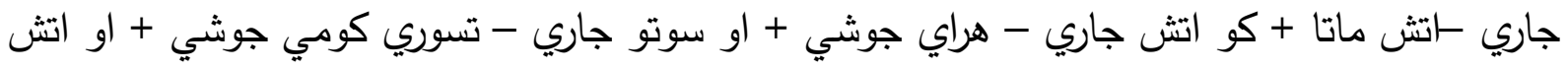

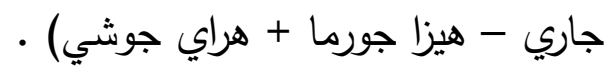


وتري الباحثة ان ذلك يرجع الي تدريبات كروس فيت التي ادت الي تحسن مستوي التكنيك الهجومي لارتباطها بمتطلبات اداء مهارات ذللك التكنيك (قيد البحث) كما ان البرنامج التدريبي المقترح والمبني علي اسس علمية يتقق مع الهدف من تطبيقه وهو تحسين حالة اللاعب الفنية وتاخير ظهور الاجهاد لديه

وبذلك يتحقق الفرض الثالث الذي ينص علي 'توجد فروق دالة احصائيا بين القياسين القبلي والبعدي في بعض مهارات التكتيك الهجومي ( قيد البحث ) لصالح القياس البعدي"

وتشير نتائج جدول (6) الي وجود علاقة ارتباطية بين متغيرات الجهد البدني والتحمل الخاص والتكنيك الهجومي لمهارات الناجي وازا (قيد البحث)حيث كانت العلاقة بين تركيز حامض اللاكتيك قبل وبعد المجهود وبين تحمل الاداء وتحمل السرعة علاقة طردية سالبة فكلما قل تركيز لاكتات الدم كلما زاد عدد مرات الاداء مع ثبوث الزمن في اختبارات تحمل الاداء وتحمل السرعة بينما اشارت نتائج جدول (6) الي وجود علاقة طردية موجبة بين تركيز لاكتات الدم وبين تحمل القوة حيث انه كلما قل تركيز لاكتات الدم قل زمن

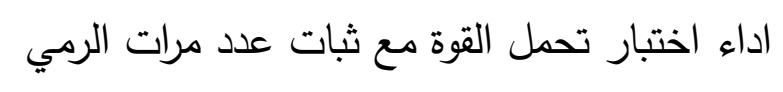

كما اشارت نتائج جدول (6) الي وجود علاقة طردية سالبة بين تركيز لاكتات الدم وبين مهارات التكنيك الهجومي فكلما قل تركيز لاكتات الدم كلما زاد مستوي التكنيك الهجومي لدهارات الناجي وازا قيد البحث

كما اشارت نتائج جدول (6) الي وجود علاقة طردية موجبة بين تحمل الاداء وتحمل السرعة وبين مهارات التكنيك الهجومي قيد البحث فكلما زاد التحمل اي زادت عدد الرميات مع ثبوت الزمن كلما تحسن مستوي اداء التكنيك الهجومي ،كما اشارت الي وجود علاقة طردية سالبة بين تحمل القوة وبين مهارات التكنيك الهجومي قيد البحث حيت انه كلما قل زمن الاداء في اختبار تحمل القوة مع ثبات عدد مرات الاداء كلما تحسن مستوي اداء مهارات التكنيك الهجومي لمهارات الناجي وازا (قيد البحث) وتعزو الباحثة هذه العلاقة الارتباطية الي طبيعة تدريبات كروس فيت التي تعمل علي تهيئة اللاعب بدنيا وفسيولوجيا لمواجهة متطلبات تكنيك الهجوم في رياضة الجودو وما يحتاجه ذلك التكنيك من تحمل خاص للاداء والسرعة والقوة لتحقيق الهجمات بنجاح وبذلك يتحقق الفرض الرابع الذي ينص علي 'توجد علاقة 
ارتباطية موجبة بين متغيرات الجها البدني والتحمل الخاص والتكنيك الهجومي لمهارات الناجي وازا (قيد (البحث)

\section{الإستخلاصات والتوصيات:

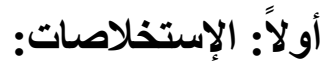

فى ضوء أهداف البحث وفروضه، وفى حدود عينة البحث والاداوات المستخدمة، وكذلك المعالجات الإحصائية المستخدمة فى البحث أمكن التوصل إلى الإستخلاصات التالية:

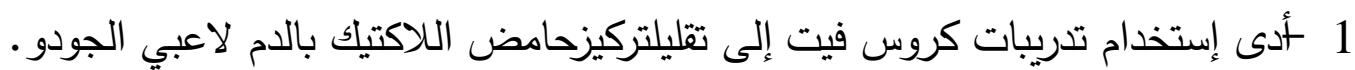

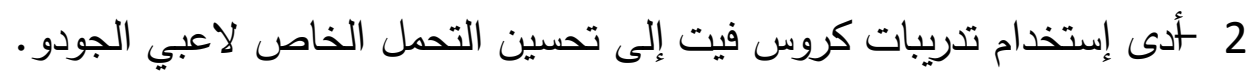
3 أدى إستخدام تدريبات كروس فيت إلى تحسين مستوي التكنيك الهجومي لاعبي الجودو . لإسيات

\section{ثانياً: التوصيات:}

بناءاً على النتائج التى تم التوصل إليها توصى الباحثة بما يلى:

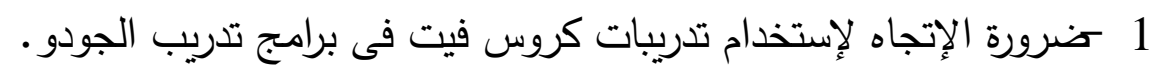

2 +لإهتمام بإستخدام تدريبات كروس فيت خلال فترات الإعداد الخاص لأهميته فى تطوير القدرات الفسيولوجيةوالبدنية للاعبين.

3 +إجراء بحوث فى مجال رياضة الجودو بإستخدام تدريباتكروس فيت لفاعليته فى تطوير وتحسين الأداء في مراحل سنية مختلفة وعلي مهارات مختلفة. 


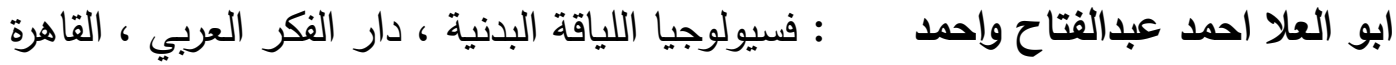
نصر الدين رضوان ( 2003) : برنامج تدريبي مقترح وفقا لنظم انتاج الطاقة لتحسين القدرة احمد ابراهيم عزب (2009) الهوائية واللاهوائية وبعض المتغيرات البدنية والتكوين الجسمي للاعبي المبارزه ، مجلة بحوث التربية الرياضية، جامعة الزقازيق، العدد 43 : اثر استخدام التدريب المركب علي تحسين مستوي الاداء احمد حرب (بو زايدة (2018) لبعض المهارات الهجومية برياضة الجودو، مجلة جامعة

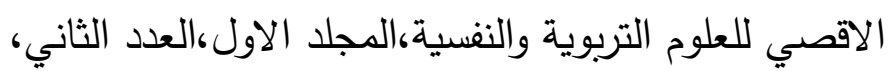
مارس

: برنامج تدريبي مقترح باستخدام تدريبات السرعة الفائقة ايمان محمد تحمل (براهيم (2012) لتحسين المستوي الرقمي لناشئات مسابقات المسافات القصيرة ، رسالة ماحستير ، كلية التربية الرياضية للبنات ، جامعة الزقازيق

: تاثير استخدام اربطة المقاومة المطاطة علي بعض عناصر بسنت سعد الدين خليل (2006)

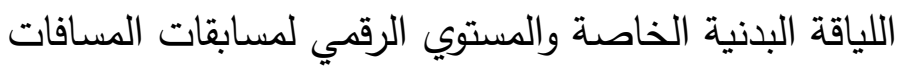

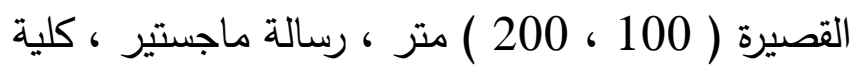
التربية الرياضية بنات الجزيرة ، جامعة حلوان

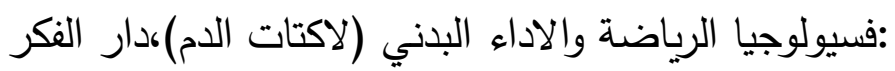
بهاء الدين (براهيم سلامة

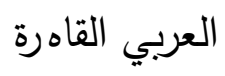
: الخصائص الكيميائية والحيوية والفسيولوجية للرياضة ،دار (2000) الفكر العربي ، القاهرة بهاء الاين ابراهيم سلامة (2008) 
فاعلية تدريبات التاييو علي مستوي المهارات الهجومية :

رانيا تحمد عبد الجواد (2006)

وتتمية التحمل الخاص لاي لاعبات الكاراتيه،رسالة

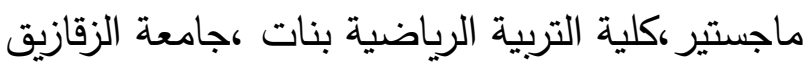

: التدريب الرياضي ،مركز الكتاب للنشر ، القاهرة

ريسان خربيط ، ابو العلا عبد

(2016) (لفتاح (2016)

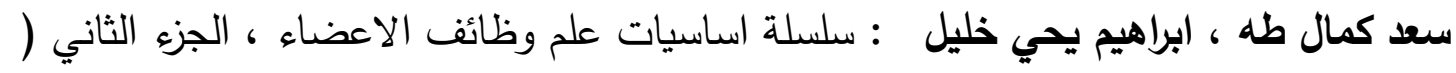
الام ) ، مكتب السعادة ، القاهرة

(2004)

شريف محمد عادل شوقي (2001) تاثير مجهود بدني حتي الانهاك علي بعض المتغيرات ،

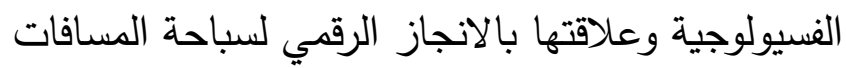

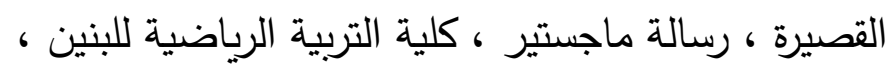
جامعة الزقازيق

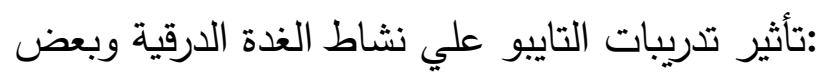
شيرين احمد يوسف (2005)

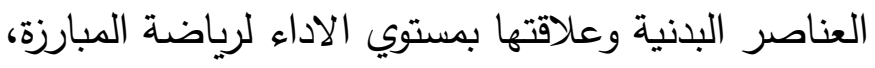
مجلة بحوث التربية الرياضية،المجلد الثاني،كلية التربية الرياضية للبنات،جامعة الزقازيق : تاثير التدريبات التبادلية للباليستي والفالون دافا علي بعض التضات صفاء صالح حسين (2008)

المتغيرات الوظيفية والعقلية لدي لاعبات الكاراتيه ،المجلة العلمية لكلية التربية الرياضية ، الاسكندرية

: تاثير تدرببات الكروس فيت علي بعض المتغيرات البدنية طه احمد محمد بدوي (2018)

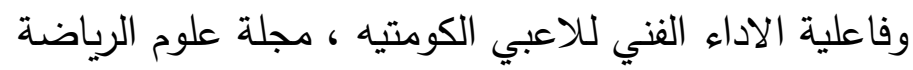
، المجلد 31 ، عدد يونيه ،كلية التربية الرياضية جامعة لاهيه المنيا

تأثير استخدام بعض الاساليب الفسيولوجية لتقنين حمل عصام عبد الحميد (2000)

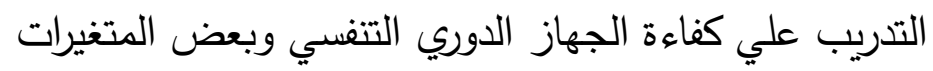
البدنية والمهارية لاي ناشئ كرة القدم : التدريب الرياضي نظريات وتطبيقات ، ط12 ، د دار عصام عبد الخالق (2005) 


$$
\text { المعارف ، الاسكندرية }
$$

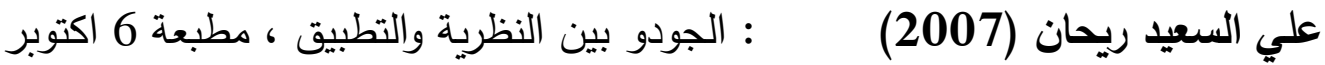

$$
\text { 6المنصورة }
$$

:الاسس الفسيولوجية للانشطة الحركية ، مركز الكتاب للنشر

$$
\text { علي جلال الاين (2006) - (20) }
$$

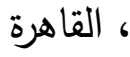

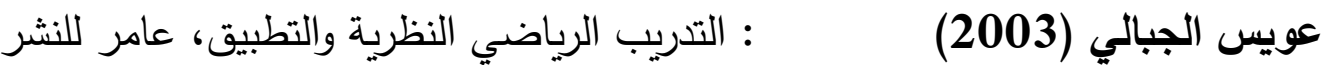

$$
\begin{aligned}
& \text { والطباعة،المنصورة }
\end{aligned}
$$

: فنون الجودو ،مذكرة غير منشورة ، كلية التربية الرياضية

فايزة خضر ، نيفين حسين

$$
\text { للبنات ، جامعة الزقازيق }
$$

: تقنيات فن الجودو ،مركز الكتاب للنشر ، ط2 ، القاهرة

$$
\text { (2007) }
$$

فايزة احمد خضر

(2008)

:الجودو بين النظرية والتطبيق ، دار الفكر العربي ، القاهرة

: تاثير برنامج تدريبي مقترح لتنمية الاداءات الحركية علي

محد السيد معروف حسن (2008) فاعلية الاداء المهاري لناشئ الجودو ، رسالة ماجستير ، كلية التربية الرياضية للبنين ، جامعة المنصورة

: دليل المدرب للتدريب ،دار شمس للطباعة ، القاهرة محمد حامد شداد (2009) : تاثير تدريبات لبعض القدرات البدنية الخاصة علي فاعلية محمد صابر شفيق (2013)

، الاداء المهاري والخططي لناشئ الكاراتيه ،رسالة ماجستير كلية التربية الرياضية ، جامعة المنصورى

$$
\text { بيولوجيا الرياضة ،دار بانسيه للطباعة ، الزقازيق: }
$$

محمد صبحي عبد الحميا (2005) : الخرائط التكتيكية وفاعلية استخدام مداخل الهجوم لدي محمد لبيب عبد العزيز (2012) لاعبي مسابقة القتال الفعلي (كومتيه) كمرشد لتخطيط البرامج برياضة الكاراتيه ،رسالة ماجستير ، كلية التربية الرياضية 
ل ل لبنين ، جامعة بنها

: تأثير استخدام التتريبات الباليستيه علي بعض المتغيرات

محمود محمود السيد (2010)

البدنية وفاعلية الاداء المهاري لدي لاعبي الجودو ،رسالة

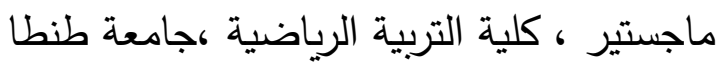

: تاثير تدريبات تحمل اللاكتيك علي معدل العمل الهجومي

محمود تحما محمود عبدالرحيم

لدي لاعبي المبارزة ، رسالة ماجستير ، كلية التربية الرياضية

(2001)

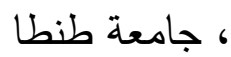

: التدريب الرياضي الحديث (تخطيط وتطبيق وقيادة) ، ط33 :

مفتي ابراهيم حماد (2001) ، دار الفكر العربي، القاهرة

: فنون الجودو ، مذكرة غير منشورة ، ط2 ، كلية التربية

نيفين حسين محمود (2007)

الرياضية للبنات ،جامعة الزقازيق

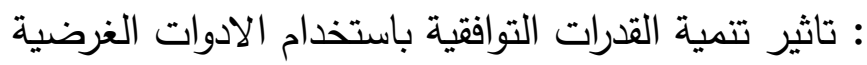

نيفين حسين محمود (2008)

علي مستوي اداء الجمل الخططية والثقة الرياضية في رياضة

الجودو ، مجلة بحوث التربية الرياضية ، جامعة الزقازيق

: تاثير برنامج تدريبي لبعض المهارات الهجومية المركبة :

هاني عادل مرسي (2004)

علي مستوي اداء لاعبي الجودو ،رسالة دكتوراة ، كلية التربية

الرياضية جامعة طنطا

: تأثير إستخدام تدريبات البليو متريك للرجلين لتنمية القدرة

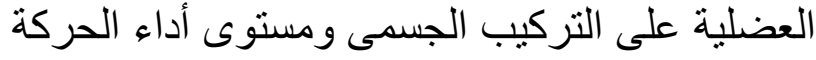

وائل جلال الأسيوطى (2005)

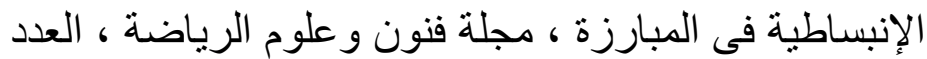

(3) كلية التربية الرياضية ، جامعة حلة فلونان.

ياسر يوسف عبد الرؤف (2005) : رياضة الجودو والقرن الحاري والعشرين ، دار الاسراء

للطباعة، القاهرة

الأسس العلمية لرياضة الجودو، مركز النعام للنشر، القاهرة،

يحي الصاوي محمود(1996)

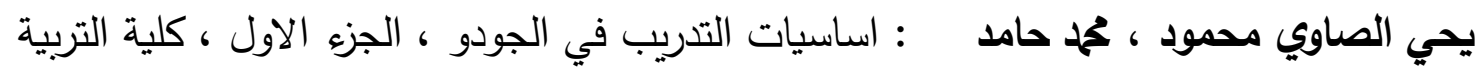




\section{شداد ، ياسر يوسف عبد الرؤف الرياضية بالهرم ، جامعة حلوان}

(2005)

\section{ثانيا : المراجع الاجنبية}

(38) Aleksander Osipov et : the use of functional training crossfit methods al(2017) to improve the levelof special training of athletes who specialize in combat sambo .journal of physical education and sport ,30 september

(39) Barfield ,J.P , \& : Effect of crossfit on health related physical Anderson,A( 2014) fitness , A pilot study .journal of sport and human performance, $2(1)$.

(40) Beachle, T \& Earle , R : Essentials of Strength Training and (2000) Conditianing $2^{\text {nd }}$ ed. Human Kinetics

Bomba, $t$ (1999) : Peridization Training for Sport Human Kinetics Edward Dias,. (2008) : The Resistance-Band Workout Deck-For men Fleck S.and Kramer : Designing resistance training program $; 3^{\text {rd }}$ W.J( 2004) ed., Human Kinetics Champaign,New York USA,

Harris .D(2001)

: Sports Psychology ,apublication of leisure press, champaing, Illinois,2ed ed, Ontario Canada

Goins , Justin

Michael( 2014)
: physiological and performance effects of crossfit .diss , university of Alabama libraries

Melgen James,. (2004) : Resistance Band Workout: A Simple Way to 
Tone and Strengthen Your Muscles, ISBN13: 9781856487245. 128 p.

ثالثا : مراجع الثبكة الدولية للمعلومات

(47) https://www.albayan.ae/five-senses/mirrors/2014-10-01-1.2212415

(48) http:// www.hayatouki.com/sport/content/2451644

(49) http:// www.jcope.uobaghdad.edu.iq 